\title{
Néctar misto de umbu (Spondias tuberosa Arr. Câmera) e mangaba (Hancornia Speciosa Gomes): elaboração e avaliação da qualidade
}

\author{
Mixed nectar of imbu (Spondias tuberosa Arr. Camera) and mangaba \\ (Hancornia Speciosa Gomes): elaboration and quality evaluation
}

\section{Lana Leite de Almeida Lima', Ana Mara Oliveira e Silva', Igor Macedo Ferreira ${ }^{1}$, Tatiana Pacheco Nunes², Michelle Garcêz de Carvalho ${ }^{* *}$ (])}

\author{
1 Universidade Federal de Sergipe (UFS), Departamento de Nutrição, São Cristóvão/SE - Brasil \\ 2 Universidade Federal de Sergipe (UFS), Departamento de Tecnologia de Alimentos, São Cristóvão/SE - Brasil
}

\section{*Corresponding Author}

Michelle Garcêz de Carvalho, Universidade Federal de Sergipe (UFS), Departamento de Nutrição, Cidade Universitária Professor José Aloísio de Campos, Av. Marechal Rondon, s/n, Jardim Rosa Elze, CEP: 49100-000, São Cristóvão/SE - Brasil, e-mail: michellegarcezufs@gmail.com

Cite as: Mixed nectar of imbu (Spondias tuberosa Arr. Camera) and mangaba (Hancornia Speciosa Gomes): elaboration and quality evaluation. Braz. J. Food Technol., v. 21, e2017034, 2018.

Received: Mar. 21, 2017; Accepted: May 14, 2018

\section{Resumo}

Objetivou-se elaborar três formulações de néctar misto de umbu e mangaba, além de avaliá-las quanto às suas características microbiológicas, sensoriais, físico-químicas e químicas. Antes da elaboração do néctar, três marcas de polpas de umbu e duas marcas de polpas de mangaba foram avaliadas físico-quimicamente ( $\mathrm{pH}$, acidez total titulável, sólidos solúveis totais, ratio, vitamina C) e quantificados os fenólicos totais. Escolhida a marca da polpa de cada fruta, iniciou-se a elaboração dos néctares simples (umbu ou mangaba), seguida da avaliação microbiológica e análise sensorial prévia, para encontrar a doçura ideal. Posteriormente, três formulações de néctar misto foram preparadas, sendo a formulação 1 composta por $25 \%$ umbu e $25 \%$ mangaba; a formulação 2 composta por $20 \%$ umbu e $30 \%$ mangaba, e a formulação 3 composta por $30 \%$ umbu e $20 \%$ mangaba, as quais foram avaliadas microbiológica, sensorial, físico-química e quimicamente. As amostras de néctares estavam seguras microbiologicamente. As três formulações de néctar misto apresentaram a mesma aceitabilidade, com índice de aceitação acima de 70\%. Além disso, apresentaram os mesmos sólidos solúveis totais, fenólicos totais e atividade de sequestrar o radical difenil-picril-hidrazina. Contudo, a formulação 2 foi a mais indicada do ponto de vista nutricional e a formulação 3, a mais indicada para aplicação comercial.

Palavras-chave: Frutas regionais; Bebida mista; Aceitação sensorial.

\section{Abstract}

The objective was to elaborate three umbu and mangaba mixed nectar formulations, as well as to evaluate their microbiological, sensory, physicochemical and chemical characteristics. Before preparing the nectars, three brands of umbu pulp and two brands of mangaba pulps were physico-chemically evaluated $(\mathrm{pH}$, total titratable acidity, total soluble solids, ratio, vitamin $\mathrm{C}$ ) and the total phenolics quantified. After choosing which pulp brands to use, the simple nectars (umbu or mangaba) were prepared, followed by a microbiological evaluation and prior sensory analysis to find the ideal sweetness. Subsequently, three formulations of the mixed nectar were prepared, where Formulation 1 was composed of $25 \%$ umbu and $25 \%$ mangaba, formulation 2 was composed of $20 \%$ umbu and $30 \%$ mangaba and formulation 3 was composed of $30 \%$ umbu and $20 \%$ mangaba, and the three formulations submitted to microbiological, sensory, physico-chemical and chemical evaluations. The nectar samples were microbiologically safe. The three formulations of mixed nectar showed the same acceptability with an acceptance rate above $70 \%$. In addition, they presented the same total soluble solids and total phenolics contents and the same diphenyl-picryl-hydrazine radical sequestering activity. However, formulation 2 was the most indicated from a nutritional point of view, and formulation 3 the most suitable for commercial applications.

Keywords: Regional fruits; Mixed drink; Sensory acceptance. 


\section{Introdução}

O Brasil é o maior produtor mundial de frutas in natura. Contudo, por serem perecíveis, grande parte dessas frutas sofre deterioração em poucos dias e, consequentemente, essa característica dificulta sua comercialização, especialmente a longas distâncias (MORAIS et al., 2010). As frutas, além de saborosas, são fornecedoras insubstituíveis de minerais (potássio, zinco, cobre, magnésio, cálcio, entre outros), vitaminas (especialmente vitamina $\mathrm{C}$ ), fibras e outros compostos (flavonoides, fenólicos, carotenoides), sendo amplamente recomendadas para prevenção de doenças cardiovasculares, diabetes mellitus tipo 2 e alguns tipos de câncer (FAO, 2005; ABOUL-ENEIN et al., 2013). Os compostos fenólicos têm sido associados à capacidade antioxidante em alimentos ricos nestes compostos e estão relacionados à ingestão de frutas e vegetais e à redução de riscos de certas doenças, tornando cada vez maior o interesse por estas substâncias (HAMINIUK et al., 2012).

O umbu (Spondias tuberosa Arr. Câmara) e a mangaba (Hancornia speciosa Gomes) são frutas bastante conhecidas, porém pouco conhecidas cientificamente (SILVA, 2006). Plantios comerciais são inexistentes e as frutas comercializadas são resultantes do extrativismo (SANTOS et al., 2012). Essas frutas são geralmente consumidas in natura ou nas formas de doce, compota, suco, licor, vinho, sorvete ou polpa congelada (LORENZI et al., 2006; SAMPAIO; NOGUEIRA, 2006). O umbu é uma fruta globosa ou ovoide, provida de polpa suculenta, com sabor doce acidulado e muito agradável (LORENZI et al., 2006), além de rica em vitamina C e minerais (cálcio, fósforo e ferro) (BASTOS et al., 2016). A mangaba (Hancornia speciosa Gomes) é fonte de ferro, destacando-se também pelo alto conteúdo de vitamina $C$, cerca de 200 a 300 mg/100 g de polpa, quando comparada com outros frutos, como cajá (17,27 mg/100 g de polpa) e caqui (13,18 mg/100 g de polpa) (CARVALHO et al., 2004; ELIAS et al., 2008; TEMÓTEO et al., 2012). O fruto é do tipo baga elipsoide ou arredondado, com 2 a $6 \mathrm{~cm}$, exocarpo amarelo, com manchas avermelhadas (dependendo da variedade), polpa bastante doce, carnoso-viscosa e ácida, contendo sementes discoides (LEDERMAN et al., 2000).

Diante do potencial comercial das frutas brasileiras, a indústria de alimentos tem investido na elaboração de néctares de frutas em forma de blends, com os quais se produzem bebidas nutritivas e com aceitação sensorial e comercial (MATTIETTO et al., 2007; ASSUMPÇÃO et al., 2013). De acordo com o Decreto n. ${ }^{\circ} 6.871$ de 4 de junho de 2009 (BRASIL, 2009), néctar é a bebida não fermentada, obtida da diluição em água potável da parte comestível do vegetal ou de seu extrato, adicionada de açúcares, destinada ao consumo direto. Por sua vez, blends são misturas de sucos ou polpas de frutas, feitos com a finalidade de melhorar as características organolépticas e/ou dos componentes isolados, além de potencializar a parte nutricional do produto, seja pelo alto teor em vitaminas ou pelas características funcionais (MATTIETTO, 2005).

Contudo, estudos científicos com uso da polpa de umbu e mangaba na elaboração de blends ainda não foram realizados. Dessa forma, acredita-se que um blend com frutas regionais (umbu e mangaba) poderá ser uma alternativa para o melhor aproveitamento tecnológico dessas matérias-primas, assim como para a sua valorização comercial em outras regiões do Brasil. Diante das considerações acima, o presente estudo objetivou desenvolver formulações de néctar misto de umbu e mangaba, além de avaliá-las quanto às suas características microbiológicas, sensoriais, físico-químicas e químicas.

\section{Material e métodos}

\subsection{Questão ética}

Este trabalho foi previamente aprovado pelo Comitê de Ética em Pesquisa da Universidade Federal de Sergipe, em 14 de outubro de 2016, protocolo sob n. ${ }^{\circ} 1.279 .792$. Como critérios de exclusão, foram considerados os seguintes fatores: possuir alergia ou intolerância a algum ingrediente utilizado na elaboração do néctar; idade inferior a 17 anos e superior a 50 anos; não gostar de néctar, e as pessoas que não assinaram o Termo de Consentimento Livre e Esclarecido (TCLE).

\subsection{Caracterização físico-química e química das polpas (umbu e mangaba) e do néctar misto}

Com a finalidade de escolher uma marca de polpa com características físico-químicas aceitáveis pelos padrões de identidade e qualidade (BRASIL, 2000) ou que apresentasse maior conteúdo de fenólicos totais, polpas congeladas de umbu de três marcas e de mangaba de duas marcas comerciais foram adquiridas em supermercados na cidade de Aracaju. De cada marca, foram avaliadas as características físico-químicas de três lotes de polpas. As polpas de umbu e mangaba, e os néctares foram analisados em triplicata, quanto aos seguintes aspectos: pH, com auxílio de um potenciômetro (Jenway, 3505, Inglaterra) (IAL, 2005); acidez total titulável (ATT), por titulação com $\mathrm{NaOH} \mathrm{0,1} \mathrm{molar,}$ expressa em porcentagem de ácido cítrico/100 g de polpa e/ou néctar (IAL, 2005); sólidos solúveis totais (SST) expressos em ${ }^{\circ}$ Brix (HORWITZ, 1997); fenólicos totais (FT), por meio do método Folin-Ciocalteu (SWAIN; HILLIS, 1959), expresso em miligramas de ácido gálico/100 g polpa e/ou néctar. O ratio foi calculado por meio da relação entre SST e ATT, segundo Reed et al. (1986). Além das análises citadas acima, o conteúdo de vitamina $C$ foi verificado no néctar misto, com resultados expressos em miligramas de ácido ascórbico por 100 mL néctar (HORWITZ, 1997), e a capacidade antioxidante, pelo método do radical DPPH (2,2-diphenyl-1-picrylhydrazyl), apresentando o percentual de varredura desse radical (BRAND-WILLIAMS et al., 1995). 


\subsection{Preparo do néctar}

Diante das características físico-químicas das polpas de umbu e mangaba, optou-se pela marca que mais se destacou quanto aos parâmetros avaliados. Para a elaboração de néctar simples e néctar misto, foram utilizados os seguintes ingredientes: polpa de umbu pasteurizada (Pomar), polpa de mangaba pasteurizada (Pomar), açúcar cristalizado (Caeté) e água mineral (Indaiá). Os ingredientes foram homogeneizados em liquidificador (Wallita, Rl2035, Brasil), em velocidade 4 por dois minutos. Posteriormente, procedeu-se à pasteurização do néctar em fogão (Bosch, Style Grill, Brasil) a $90^{\circ} \mathrm{C}$ por dois minutos; em seguida, realizou-se o resfriamento do néctar em banho de gelo até $0{ }^{\circ} \mathrm{C}$. Depois de preparados, foram prontamente acondicionados em garrafas de polietileno tereftalato com tampa rosqueável, com capacidade para dois litros, lacradas, sendo então armazenados sob refrigeração $\left(4{ }^{\circ} \mathrm{C}\right)$ por, no máximo, 24 horas até o início da avaliação microbiológica e sensorial.

\subsection{Análises microbiológicas dos néctares}

As análises microbiológicas dos néctares foram realizadas antes do teste sensorial, com o intuito de se garantir a segurança aos provadores. Os néctares foram avaliados de acordo com Silva et al. (2010), empregando-se a técnica do número mais provável (NMP) para a contagem de coliformes totais $\left(35^{\circ} \mathrm{C}\right)$, e Salmonella sp., pelo método de presença ou ausência.

\subsection{Análise sensorial prévia}

Com a finalidade de se encontrar o melhor grau de doçura, foram realizados testes preliminares de néctar com polpa de umbu e néctar com polpa de mangaba. A análise sensorial foi executada com três formulações de néctar de umbu e três formulações de néctar de mangaba, com diferentes teores de sólidos solúveis finais (14, 16 e $18{ }^{\circ}$ Brix), sendo avaliada a doçura $A$ (50\% de polpa, $7 \%$ de sacarose $+43 \%$ de água mineral), a doçura B (50\% de polpa, $8 \%$ de sacarose $+42 \%$ de água) e a doçura C (50\% de polpa, 9\% de sacarose $+41 \%$ de água). A avaliação sensorial foi realizada pela técnica de apresentação monádica e casualizada, com auxílio de 30 provadores não treinados. Somente foram avaliados os néctares que se encontravam de acordo com a Resolução n. ${ }^{\circ} 12$, relativa à contaminação microbiológica de alimentos (BRASIL, 2001). Os participantes foram convidados a ler e assinar o TCLE antes de realizaremas análises. As amostras foram avaliadas em cabines individuais, sob luz branca. Aproximadamente $20 \mathrm{~mL}$ de cada amostra foram servidos a $10^{\circ} \mathrm{C}$, em copos de polipropileno codificados com algarismos de três dígitos. Foi verificada a doçura do néctar pelo teste "Escala do Ideal" ( 1 = muito mais fraco que o ideal a $7=$ muito mais intenso que o ideal) (STONE; SIDEL, 1985; MATTIETTO, 2005; MINIM, 2013).

\subsection{Formulação do néctar misto de umbu e mangaba}

A análise de variância (ANOVA) e o teste de Tukey (IBM SPSS Statistics ${ }^{\circledR}$, 2012) foram realizados para a comparação das notas médias dadas pelos 30 provadores na análise sensorial da doçura do néctar simples (apenas um tipo de polpa), adotando-se nível de significância de $5 \%$ de probabilidade. Após a identificação do grau de doçura de melhor aceitação pelos provadores, iniciou-se a formulação do néctar misto. É importante salientar que as respectivas quantidades de polpa de umbu e mangaba utilizadas na elaboração do néctar obedeceram ao mínimo (20\% de polpa) preconizado pela legislação brasileira (BRASIL, 2003), no que se refere às bebidas elaboradas com duas frutas.

Foram elaboradas três formulações (F1, F2 e F3) de néctar misto, variando apenas as concentrações de polpas. A proporção dos ingredientes para produção de $100 \mathrm{~mL}$ de néctar misto foi a seguinte: F1(25\% de polpa de umbu, $25 \%$ de polpa de mangaba, 7,5\% de açúcar e 42,5\% de água mineral), F2 (20\% de polpa de umbu, 30\% de polpa de mangaba, 7,5\% de açúcar e 42,5\% de água mineral) e F3 $(30 \%$ de polpa de umbu, $20 \%$ de polpa de mangaba, $7,5 \%$ de açúcar e 42,5\% de água mineral). Os néctares mistos foram preparados conforme descrito no item 2.3.

\subsection{Avaliação sensorial do néctar misto}

A análise sensorial de três formulações de néctar misto foi realizada como descrito no item 2.5, porém com 65 provadores. As formulações de néctar misto foram avaliadas quanto a sua preferência (teste de ordenação), aceitação (escala hedônica) e a intenção de compra. A aceitação foi verificada pela escala hedônica estruturada de nove pontos ( 1 = desgostei muitíssimo a 9 = gostei muitíssimo), em relação aos parâmetros aparência, aroma, cor, sabor, doçura e impressão global. A escala de intenção de compra variou de um a cinco e apresentou a seguinte classificação: 1 = certamente não compraria; 2 = provavelmente não compraria; 3 = talvez comprasse, talvez não; 4 = provavelmente compraria, e 5 = certamente compraria (STONE; SIDEL, 1985; MINIM, 2013). A interpretação dos resultados da preferência foi realizada de acordo com a metodologia estabelecida por Friedman (MINIM, 2013). Foi avaliado o Índice de Aceitabilidade (IA), por meio da expressão $\mathrm{I} A(\%)=A \times 100 / B$, em que, $A=$ nota média obtida para o produto e $\mathrm{B}=$ nota máxima dada ao produto. Para que um produto seja considerado como bem aceito, ele deve apresentar IA $\geq 70 \%$ (DUTCOSKY, 2011).

\subsection{Análise estatística}

Com auxílio do software IBM SPSS versão 21 (IBM, 2012), os dados das características sensoriais e físico-químicas, e da atividade antioxidante foram submetidos à análise 
de variância (ANOVA) para medidas repetidas, a fim de verificar a homogeneidade das médias. As médias que se apresentaram homogêneas $(p>0,05)$ foram submetidas ao teste de Tukey. Os valores de $p$ foram considerados significativos quando menores que 0,05.

\section{Resultados e discussão}

\subsection{Caracterização físico-química e fenólicos totais de polpas de umbu e mangaba}

A Tabela 1 apresenta a caracterização físico-química da polpa de umbu e mangaba. Observou-se que não houve diferença estatística entre as marcas de polpa de umbu, havendo apenas diferença significativa para a acidez total titulável na marca $\mathrm{C}$ em relação às marcas $A$ e $B$. No que se refere à polpa de mangaba, observou-se apenas diferença $(p<0,05)$ entre as marcas $A$ e $C$, para os fenólicos totais, das quais a marca $\mathrm{C}$ apresentou maior conteúdo.

Os resultados das análises físico-químicas demonstraram que as polpas de mangaba avaliadas estavam de acordo com os padrões de identidade e qualidade (BRASIL, 2000), os quais estabelecem que a polpa de mangaba deve possuir, no mínimo: $8^{\circ}$ Brix, pH 2,8 e acidez total titulável $0,7 \mathrm{~g}$ de ácido cítrico/100 g de polpa. Embora não haja padrões legais de identidade e qualidade para polpa de umbu, as características físico-químicas observadas na polpa desse fruto, como pH $(2,60$ a 2,64) e SST (6 a 7,67), foram equivalentes ao encontrado na literatura: pH (2,58 a 2,64) (HONORATO et al., 2015) e SST (5,7 a 7,74) (MACHADO et al., 2008; HONORATO et al., 2015).

O ratio (relação SST e ATT) observado nas polpas de mangaba $(2,51$ a 3,05$)$ foi maior que o encontrado na polpa de umbu (1,42 a 1,73) (Tabela 1). Esse parâmetro indica o balanço de ácidos e açúcares; assim, quando os valores desta relação são altos, significa que o fruto está em bom grau de maturação, pois esse grau aumenta quando há decréscimo de acidez e alto teor de SST, decorrentes da maturação (CHITARRA; CHITARRA, 2005). O ratio é um dos melhores parâmetros de avaliação do sabor, sendo mais representativo do que a mensuração isolada de açúcares e acidez (PINTO et al., 2003).
No que se refere ao teor de fenólicos totais (FT), observou-se que a polpa de mangaba (92,50 a 107,18 mg ácido gálico/100 g de polpa) possui quase três vezes mais FT que a polpa de umbu (31,29 a 44,6 mg ácido gálico/100 g de polpa) (Tabela 1). Rufino et al. (2010) afirmam que a mangaba é uma boa fonte de compostos fenólicos, apresentando, em média, $169 \pm 21,5$ mg ácido gálico/100 g de polpa. Segundo Melo e Andrade (2010), os valores de FT de umbu podem variar de 31,47 a 39,6 mg/100 g, pois a variação ocorre de acordo com o grau de maturação do umbu. Assim, os valores de FT encontrados neste estudo (Tabela 1) estão próximos aos relatados pelos autores. Contudo, o umbu, independentemente do estado de maturação, apresenta menor teor de fenólicos totais do que outras frutas, como kiwi (108 mg/100 g), maçã (150 mg/100 g) e pera (120 mg/100 g) (IMEH; KHOKHAR, 2002). O cultivo extrativista do umbu tem impedido a padronização da matéria-prima pelas indústrias de polpas. Além disso, ainda não há no Brasil um Padrão de Identidade e Qualidade para polpa de umbu, o que dificulta a fiscalização de sua qualidade conforme parâmetros oficiais (MACHADO et al., 2008).

Os fenólicos totais (FT) apresentam a capacidade de sequestrar radicais livres, atuando como agentes redutores de metais de transição, agindo tanto na etapa de iniciação como na propagação do processo oxidativo (ARAÚJO, 2011). Alimentos ricos em compostos fenólicos podem ser aplicados na fabricação de cosméticos fotoprotetores (DAL'BELO, 2008), aditivos alimentícios (conservantes, corantes), antibióticos, anti-inflamatórios e medicamentos para o tratamento de doenças cardiovasculares e hipertensão (BRAVO, 1998). Assim, a polpa de mangaba destaca-se como fonte potencial de compostos fenólicos, uma vez que apresenta duas a três vezes mais FT que a polpa de umbu avaliada (Tabela 1).

Baseada nas características físico-químicas avaliadas nas polpas de umbu e mangaba, observou-se que não houve diferença estatística entre as marcas para a maioria dos parâmetros avaliados, o que dificultou a escolha da marca para elaboração do néctar misto com ambas as polpas. Dessa forma, optou-se pela marca C, por esta

Tabela 1. Características físico-químicas e fenólicos totais de polpas de umbu e mangaba.

\begin{tabular}{ccccccc} 
& \multicolumn{7}{c}{ Parâmetros analíticos $^{*}$} \\
\cline { 2 - 7 } Polpa & Marca & pH & ATT & SST & Ratio & FT \\
Umbu & A & $2,61 \pm 0,17^{\mathrm{a}}$ & $4,56 \pm 0,64^{\mathrm{a}}$ & $7,67 \pm 0,58^{\mathrm{a}}$ & $1,71 \pm 0,31^{\mathrm{a}}$ & $39,88 \pm 8,80^{\mathrm{a}}$ \\
Umbu & $\mathrm{B}$ & $2,64 \pm 0,12^{\mathrm{a}}$ & $4,87 \pm 0,07^{\mathrm{a}}$ & $7,00 \pm 0,00^{\mathrm{a}}$ & $1,43 \pm 0,03^{\mathrm{a}}$ & $44,6 \pm 14,43^{\mathrm{a}}$ \\
Umbu & $\mathrm{C}$ & $2,68 \pm 0,26^{\mathrm{a}}$ & $3,76 \pm 0,48^{\mathrm{b}}$ & $6,00 \pm 0,00^{\mathrm{a}}$ & $1,42 \pm 0,29^{\mathrm{a}}$ & $31,29 \pm 6,57^{\mathrm{a}}$ \\
Mangaba & $\mathrm{A}$ & $3,25 \pm 0,14^{\mathrm{a}}$ & $3,21 \pm 0,83^{\mathrm{a}}$ & $9,33 \pm 0,58^{\mathrm{a}}$ & $3,05 \pm 0,84^{\mathrm{a}}$ & $92,50 \pm 2,15^{\mathrm{b}}$ \\
Mangaba & $\mathrm{C}$ & $3,26 \pm 0,12^{\mathrm{a}}$ & $3,18 \pm 0,06^{\mathrm{a}}$ & $9,00 \pm 0,00^{\mathrm{a}}$ & $2,51 \pm 0,40^{\mathrm{a}}$ & $107,18 \pm 10,39^{\mathrm{a}}$ \\
\hline
\end{tabular}

*Valores médios e desvio padrão em triplicata de três lotes de cada marca. Letras diferentes na coluna indicam diferença significativa pelo teste de Tukey $(p<0,05) ; \mathrm{pH}=$ potencial hidrogeniônico; ATT = acidez total titulável; SST = sólidos solúveis totais; FT = fenólicos totais. 
Néctar misto de umbu (Spondias tuberosa Arr. Câmera) e mangaba (Hancornia Speciosa Gomes): elaboração e avaliação da qualidade Lima, L. L. A. et al.

ter apresentado um maior teor de FT para a polpa de mangaba. De acordo com Sacramento e Souza (2000), as características físico-químicas das frutas podem variar com o fator genético, o local e o tipo de cultivo, a época de colheita e o estado de maturação.

\subsection{Análise microbiológica do néctar}

A resolução RDC n. 12 (BRASIL, 2001), que regulamenta os padrões microbiológicos para alimentos e bebidas, estabelece para bebidas não alcoólicas, como refrescos, sucos e néctares adicionados ou não de conservadores, e prontos para consumo, padrões para coliformes totais (ausência em $50 \mathrm{~mL}$ ) e ausência de Salmonella sp. (ausência em $25 \mathrm{~mL}$ ). Dessa forma, após a análise microbiológica das formulações de néctar simples e néctar misto, observou-se ausência de bastonetes positivos para coliformes totais e ausência de colônias típicas de Salmonella sp.; assim, os néctares estavam seguros do ponto de vista higiênico-sanitário para serem consumidos pelos provadores na análise sensorial.

\subsection{Análise sensorial do néctar}

\subsubsection{Aceitação sensorial e intenção de compra}

Dos 30 provadores que participaram da análise sensorial prévia da doçura dos néctares simples de umbu e mangaba, 37\% opinaram como doçura ideal para o néctar de umbu $16^{\circ} \mathrm{Brix}$ ou $18^{\circ} \mathrm{Brix}$, enquanto que $47 \%$ dos provadores escolheram $14^{\circ}$ Brix para o néctar de mangaba. Dessa forma, escolheu-se $15^{\circ}$ Brix, para elaboração do néctar misto.

Na Tabela 2 são apresentados as médias e o desvio padrão da aceitação sensorial e da intenção de compra das três formulações de néctar misto com polpa de umbu e mangaba. Esses resultados demonstram estatisticamente $(p>0,05)$ que, independentemente das proporções de polpa de umbu e mangaba adicionadas aos néctares, a aceitabilidade foi a mesma para as três formulações de néctar misto. Quanto ao gostar e desgostar, observou-se que os néctares apresentaram notas entre gostei moderadamente (7) e gostei muito (8).

Não houve diferença significativa $(p<0,05)$ para a intenção de compra entre as formulações de néctar misto, porém, no que se refere à escala de certamente compraria, a formulação 2 foi a que obteve o maior percentual (32\%), enquanto que as formulações 1 e 3 satisfizeram 23\% e $25 \%$ dos provadores, respectivamente.

\subsubsection{Preferência sensorial}

No que se refere à ordem de preferência, há diferença significativa para a preferência entre as formulações avaliadas. A formulação 3 foi a mais preferida $(p<0,05)$ entre os provadores, porém não houve preferência significativa $(p>0,05)$ entre as formulações 1 e 2 dos néctares mistos avaliados.

Os Índices de Aceitabilidade (IA) obtidos pelos atributos sensoriais das formulações F1, F2 e F3 foram, respectivamente, 95,83\%, 89,58\% e 100\%. Pode-se afirmar que as três formulações foram bem aceitas e apresentam um bom potencial de comercialização, uma vez que os resultados para os diferentes atributos foram acima de 70\% (DUTCOSKY, 2011).

\subsection{Caracterização físico-química, fenólicos totais e DPPH do néctar misto}

A Tabela 3 apresenta as médias e o desvio padrão da caracterização físico-química das três formulações de néctar misto de umbu e mangaba. Observou-se que não houve diferença significativa $(p<0,05)$ entre as formulações, para os parâmetros sólidos solúveis totais (SST), fenólicos totais (FT) e atividade de sequestro do radical difenil-picril-hidrazina (DPPH). Contudo, observou-se que a formulação 2 apresentou um maior $\mathrm{pH}(2,48)$ e vitamina C (50 mg de ácido ascórbico/100 mL de polpa), se comparada às formulações 1 e 3 . No que se refere à acidez total titulável (ATT), a formulação 3 demonstrou a maior média (6,62\%). Tais variações entre esses parâmetros

Tabela 2. Aceitação sensorial e intenção de compra das formulações de néctar misto de umbu e mangaba.

\begin{tabular}{|c|c|c|c|}
\hline \multirow{3}{*}{ Atributos sensoriais } & \multicolumn{3}{|c|}{ Formulações } \\
\hline & $\mathbf{F 1}$ & F2 & $\mathbf{F 3}$ \\
\hline & Média \pm DP* & Média \pm DP* & Média $\pm \mathrm{DP} *$ \\
\hline Aparência & $8,00 \pm 1,24^{a}$ & $8,00 \pm 1,47^{a}$ & $7,00 \pm 1,46^{a}$ \\
\hline Aroma & $7,00 \pm 1,55^{a}$ & $7,00 \pm 1,65^{a}$ & $7,00 \pm 1,56^{a}$ \\
\hline Cor & $8,00 \pm 1,33^{a}$ & $7,00 \pm 1,54^{a}$ & $7,00 \pm 1,38^{a}$ \\
\hline Doçura & $7,00 \pm 1,58^{a}$ & $7,00 \pm 1,80^{\mathrm{a}}$ & $7,00 \pm 1,86^{a}$ \\
\hline Sabor & $8,00 \pm 1,26^{a}$ & $7,00 \pm 1,46^{a}$ & $7,00 \pm 1,65^{a}$ \\
\hline Impressão global & $8,00 \pm 1,16^{a}$ & $7,00 \pm 1,41^{\mathrm{a}}$ & $7,00 \pm 1,40^{a}$ \\
\hline Intenção de Compra & $4,00 \pm 1,12^{\mathrm{a}}$ & $4,00 \pm 1,15^{\mathrm{a}}$ & $3,00 \pm 1,30^{a}$ \\
\hline
\end{tabular}

*Letras diferentes na linha indicam diferença significativa pelo teste de Tukey $(p<0,05)$; DP-Desvio padrão; F1 (Formulação 1): $25 \%$ umbu e 25\% mangaba; F2 (Formulação 2): 20\% umbu e 30\% mangaba; F3 (Formulação 3): 30\% umbu e 20\% de mangaba. 
Néctar misto de umbu (Spondias tuberosa Arr. Câmera) e mangaba (Hancornia Speciosa Gomes): elaboração e avaliação da qualidade Lima, L. L. A. et al.

Tabela 3. Caracterização físico-química, fenólicos totais e DPPH do néctar misto com umbu e mangaba.

\begin{tabular}{|c|c|c|c|}
\hline \multirow{3}{*}{ Parâmetros analíticos* } & \multicolumn{3}{|c|}{ Formulações } \\
\hline & $\mathbf{F 1}$ & $F 2$ & F3 \\
\hline & Média $\pm \mathrm{DP}$ * & Média $\pm \mathrm{DP} *$ & Média $\pm \mathrm{DP} *$ \\
\hline $\mathrm{pH}$ & $2,41 \pm 0,03^{b}$ & $2,48 \pm 0,02^{a}$ & $2,22 \pm 0,02^{c}$ \\
\hline ATT & $5,68 \pm 0,06^{c}$ & $5,99 \pm 0,12^{b}$ & $6,62 \pm 0,14^{a}$ \\
\hline SST & $15,00 \pm 0,00^{a}$ & $15,00 \pm 0,00^{a}$ & $15,00 \pm 0,00^{a}$ \\
\hline Vitamina C & $30,00 \pm 0,00^{b}$ & $50,00 \pm 0,00^{a}$ & $5,00 \pm 0,00^{\circ}$ \\
\hline Fenólicos totais & $49,69 \pm 4,04^{a}$ & $56,68 \pm 5,10^{a}$ & $55,99 \pm 5,43^{a}$ \\
\hline DPPH & $41,11 \pm 8,67^{a}$ & $41,24 \pm 5,62^{a}$ & $48,22 \pm 4,91^{\mathrm{a}}$ \\
\hline
\end{tabular}

*Valores médios e desvio padrão (DP), em triplicata de um mesmo lote de néctar misto. Letras diferentes na linha indicam diferença significativa pelo teste de Tukey $(p<0,05) ; \mathrm{pH}=$ potencial hidrogeniônico; ATT (\% ác. cítrico/100 g) = acidez total titulável; SST ( ${ }^{\circ}$ Brix) $=$ sólidos solúveis totais; Vitamina $\mathrm{C}(\mathrm{mg}$ ác. ascórbico $/ 100 \mathrm{~mL})=$ vitamina $\mathrm{C} ; \mathrm{FT}$ (mg ác. gálico/100 g) = fenólicos totais; DPPH (\% varredura) = atividade do radical difenil-picril-hidrazina; F1 (Formulação 1) = 25\% umbu e 25\% mangaba; F2 (Formulação 2 ) = 20\% umbu e $30 \%$ mangaba; F3 (Formulação 3) = 30\% umbu e 20\% de mangaba.

estão provavelmente associadas às concentrações e aos tipos de polpa adicionados aos néctares avaliados.

Os valores de $\mathrm{pH}$, nas três formulações de néctar misto (umbu e mangaba), de 2,22 a 2,48 (Tabela 3), estão abaixo de 4,5, o que dificulta o desenvolvimento de microrganismos, principalmente bactérias (FRANCO; LANDGRAF, 2005), e permite o armazenamento em temperatura ambiente $\left(25^{\circ} \mathrm{C}\right)$, se submetidos à pasteurização (ALCÂNTARA et al., 2007; GAVA, 2008). A acidez total titulável está correlacionada com o pH do alimento; no entanto, produtos alimentícios com alto teor de ácido cítrico, além de não necessitarem de adição de ácidos, torna o meio impróprio ao desenvolvimento de microrganismos patogênicos (FRANCO; LANDGRAF, 2005; GAVA, 2008).

O néctar misto contendo $20 \%$ de polpa de umbu e $30 \%$ de polpa de mangaba (F2) mostrou elevado conteúdo de vitamina C (50 mg ácido ascórbico/100 mL de néctar), sendo observado ainda que o teor de vitamina $\mathrm{C}$ aumentava com a elevação da proporção de polpa de mangaba. Embora a proporção e o tipo de polpa de fruta sejam diferentes nas formulações de néctar (F1, F2 e F3), estes não influenciaram o conteúdo de fenólicos totais e a atividade antioxidante (DPPH) dos néctares avaliados (Tabela 3). Levando em consideração a ingestão diária recomendada de vitamina $\mathrm{C}$, que é $75 \mathrm{mg}$ para mulheres e 90 mg para homens (IOM, 2000), a vitamina C encontrada na formulação 2 representa, para mulheres e homens adultos, respectivamente, $67 \%$ e $56 \%$ da necessidade diária de ingestão desse nutriente (Tabela 3), sem, contudo, exceder a 2.000 mg de vitamina C, o máximo recomendado diariamente (IOM, 2000).

Dessa forma, a formulação com maior conteúdo de vitamina $C$ (F2) é mais indicada no que se refere ao aspecto nutricional (Tabela 3), uma vez que a vitamina C exerce diversas funções no organismo humano: atua na hidroxilação da prolina e lisina, necessárias para a biossíntese de colágeno; aumenta a absorção de ferro; atua na conversão do colesterol em compostos biliares, e participa na neutralização de radicais livres (LIMA, 2011). Do ponto de vista comercial, levando-se em consideração a aceitação sensorial, a intenção de compra e a preferência, a mais viável comercialmente é a formulação 3, pois possui menos polpa de mangaba, a qual é quase duas vezes mais cara do que a polpa de umbu.

\section{Conclusão}

Diante das características observadas nos néctares avaliados, os produtos são potencialmente comercializáveis. Considerando que a aceitabilidade sensorial, a intenção de compra, os fenólicos totais e DPPH das três formulações foram os mesmos, podemos supor que, nutricionalmente, a mais indicada é a formulação 2, por possuir maior teor de vitamina $\mathrm{C}$, enquanto que, no que se refere à viabilidade comercial, a formulação 3 é a mais indicada para aplicação industrial, já que apresenta menor custo de produção.

\section{Referências}

ABOUL-ENEIN, H. Y.; BERCZYŃSK, P.; KRUK, I. Phenolic compounds: the role of redox regulation in neurodegenerative disease and cancer. Mini-Reviews in Medicinal Chemistry, v. 13, n. 3, p. 385-398, 2013. PMid:23190030.

ALCÂNTARA, S. R.; ALMEIDA, F. A. C.; SILVA, F. L. H. Emprego do bagaço seco do pedúnculo do caju para posterior utilização em um processo de fermentação semi-sólida. Revista Brasileira de Produtos Agroindustriais, v. 9, n. 2, p. 137-142, 2007. http:// dx.doi.org/10.15871/1517-8595/rbpa.v9n2p137-142.

ARAÚJO, C. R. R. Composição química, potencial antioxidante e hipolipidêmico da farinha da casca de myrciaria cauliflora (jabuticaba). 2011. 119 f. Dissertação (Mestrado em Química)Faculdade de Ciências Exatas, Universidade Federal dos Vales do Jequitinhonha e Mucuri, Diamantina, 2011.

ASSUMPÇÃO, C. F.; BACHIEGA, P.; SANTANA, A. T. M. C.; MORZELLE, M. C.; VILAS BOAS, B. M.; SOUZA, E. C. Néctar misto de mangaba (Hancornia speciosa Gomes) e cagaita (Eugenia dysenterica): perfil sensorial e características físico-químicas. 
Néctar misto de umbu (Spondias tuberosa Arr. Câmera) e mangaba (Hancornia Speciosa Gomes): elaboração e avaliação da qualidade Lima, L. L. A. et al.

Revista Brasileira de Produtos Agroindustriais, v. 15, n. 3, p. 219-224, 2013. http://dx.doi.org/10.15871/1517-8595/rbpa. v15n3p219-224

BASTOS, J. S.; MARTINEZ, E. A.; SOUZA, S. M. A. Características físico-químicas da polpa de umbu (Spondias tuberosa Arruda Camara) comercial: efeito da concentração. Journal of Bioenergy and Food Science, v. 3, n. 1, p. 11-16, 2016. http://dx.doi. org/10.18067/jbfs.v3i1.48.

BRAND-WILLIAMS, W.; CUVELIER, M.; BERSET, C. L. W. T. Use of a free radical method to evaluate antioxidant activity. Lebensmittel-Wissenschaft + Technologie, v. 28, n. 1, p. 25-30, 1995. http://dx.doi.org/10.1016/S0023-6438(95)80008-5.

BRASIL. Instrução Normativa n ${ }^{\circ}$, de 7 janeiro de 2000. Aprova o Regulamento Técnico geral para fixação dos padrões de identidade e qualidade para polpa de fruta. Diário Oficial [da] República Federativa do Brasil, Brasília, DF, 2000. Seção I, p. 54-58.

BRASIL. Ministério da Saúde. Resolução RDC n 12, de 2 de janeiro de 2001. Diário Oficial [da] República Federativa do Brasil, Brasília, DF, 10 jan. 2001, Seção I, p. 43.

BRASIL. Instrução Normativa n 12, de 4 de setembro de 2003. Aprova o Regulamento Técnico para fixação dos padrões de identidade e qualidade gerais para suco tropical; os padrões de identidade e qualidade dos sucos tropicais de abacaxi, acerola, cajá, caju, goiaba, graviola, mamão, manga, mangaba, maracujá e pitanga; e os padrões de identidade e qualidade dos néctares de abacaxi, acerola, cajá, caju, goiaba, graviola, mamão, manga, maracujá, pêssego e pitanga. Diário Oficial [da] República Federativa do Brasil, Brasília, DF, 5 set. 2003. Seção II, p. 7.

BRASIL. Decreto $n^{\circ} 6.871$, de 4 de junho de 2009. Regulamenta a Lei no 8.918, de 14 de julho de 1994, que dispõe sobre a padronização, a classificação, o registro, a inspeção, a produção e a fiscalização de bebidas. Diário Oficial [da] República Federativa do Brasil, Brasília, DF, 5 jun. 2009. Seção I, p. 9.

BRAVO, L. Polyphenols: chemistry, dietary sources, metabolism, and nutritional significance. Nutrition Reviews, v. 56, n. 11, p. 317-333, 1998. http://dx.doi.org/10.1111/j.1753-4887.1998. tb01670.x. PMid:9838798.

CARVALHO, M. O.; FONSECA, A. A. O.; SANTOS JÚNIOR, A. B.; HANSEN, D. S.; RIBEIRO, T. A. D. Caracterização física, organolépticas, química e físico-química dos frutos de mangabeiras (Hancornia speciosa Gomes) da região do Conde-BA. In: CONGRESSO BRASILEIRO DE FRUTICULTURA, 17., 2004, Pelotas. Anais... Pelotas: UFP, 2004. p. 17.

CHITARRA, M. I.; CHITARRA, A. B. Pós-colheita de frutas e hortaliças: fisiologia e manuseio. Lavras: Universidade Federal de Lavras, 2005. v. 785.

DAL'BELO, S. E. Avaliação da eficácia fotoprotetora, penetração cutânea e segurança de formulações cosméticas contendo extratos de chá verde e 'Ginkgobiloba'. 2008. 191 f. Tese (Doutorado em Ciências Farmacêuticas)-Faculdade de Ciências Farmacêuticas, Universidade de São Paulo, Ribeirão Preto, 2008.

DUTCOSKY, D. S. Análise sensorial de alimentos. Curitiba: Champagnat, 2011.

ELIAS, N. D. F.; BERBERT, P. A.; MOLINA, M. A. B. D.; VIANA, A. P.; DIONELLO, R. G.; QUEIROZ, V. A. V. Avaliação nutricional e sensorial de caqui cv Fuyu submetido à desidratação osmótica e secagem por convecção. Food Science and Technology, Campinas, v. 28, n. 2, p. 322-328, 2008. http://dx.doi.org/10.1590/ S0101-20612008000200009.

FOOD AND AGRICULTURE ORGANIZATION - FAO. Workshop de Lisboa sobre a promoção de hortofrutícolas nos países de expressão portuguesa: relatório de um workshop conjunto. Geneva: FAO, 2005.

FRANCO, B. D. G. M.; LANDGRAF, M. Microbiologia de alimentos. São Paulo: Atheneu, 2005

GAVA, A. J. Tecnologia de alimentos: princípios e aplicações. São Paulo: Nobel, 2008.

HAMINIUK, C. W.; MACIEL, G. M.; PLATA OVIEDO, M. S.; PERALTA, R. M. Phenolic compounds in fruits-an overview. International Journal of Food Science \& Technology, v. 47, n. 10, p. 20232044, 2012. http://dx.doi.org/10.1111/j.1365-2621.2012.03067.x.

HONORATO, A. C.; DIAS, C. B. R.; SOUZA, E. B.; CARVALHO, I. R. B.; SOUSA, K. S. M. Parâmetros físico-químicos de polpas de fruta produzidas na cidade de Petrolina-PE. Revista Verde de Agroecologia e Desenvolvimento Sustentável, v. 10, n. 4, p. 1-5, 2015.

HORWITZ, W. (Ed.). Official methods of analysis of the Association of Official Analytical Chemists. 16th ed. Gaithersburg: AOAC, 1997. 1298 p.

IMEH, U.; KHOKHAR, S. Distribution of conjugated and free phenols in fruits: antioxidant activity and cultivar variations. Journal of Agricultural and Food Chemistry, v. 50, n. 22, p. 6301-6306, 2002. http://dx.doi.org/10.1021/jf020342j. PMid:12381107.

INSTITUTE OF MEDICINE - IOM. Dietary reference intakes: for vitamin C, vitamin E, selenium and carotenoids. Washington: National Academy Press, 2000. p. 95-185.

INSTITUTO ADOLFO LUTZ - IAL. Métodos físico-químicos para análise de alimentos. 4. ed. Brasília: IAL, 2005. 1018 p.

INTERNATIONAL BUSINESS MACHINES - IBM. IBM SPSS statistic: application of statistical tests through release, version 21. USA: IBM, 2012.

LEDERMAN, I. E.; SILVA JÚNIOR, J. F.; BEZERRA, J. E. F.; ESPÍNDOLA, A. C. M. Mangaba (Hancornia speciosa Gomes). Jaboticabal: FUNEP, 2000. 35 p.

LIMA, J. P. Qualidade pós-colheita, atividade antioxidante in vitro e perfil volátil da mangaba (Hancornia speciosa) 
Néctar misto de umbu (Spondias tuberosa Arr. Câmera) e mangaba (Hancornia Speciosa Gomes): elaboração e avaliação da qualidade Lima, L. L. A. et al.

submetida à refrigeração e atmosfera modificada. 2011. 194 f. Dissertação (Mestrado em Ciência de Alimentos)-Faculdade de Engenharia de Alimentos, Universidade Federal de Lavras, Lavras, 2011.

LORENZI, H.; BACHER, L.; LACERDA, M. E.; SARTORI, S. Frutas brasileiras e exóticas cultivadas de consumo in natura. São Paulo: Instituto Plantarum de Estudos da Flora, 2006. 640 p.

MACHADO, S. S.; TAVARES, J. T. Q.; CARDOSO, R. L.; MACHADO, C. S.; SOUZA, K. E. P. Caracterização de polpas de frutas tropicais congeladas comercializadas no Recôncavo Baiano.

Revista Ciência Agronômica, v. 38, n. 2, p. 158-163, 2008.

MATTIETTO, R. A. Estudo tecnológico de um néctar misto de cajá (Spondias Lutea L.) e umbu (Spondias Tuberosa Arruda Câmara). 2005. 299 f. Tese (Doutorado em Tecnologia de Alimentos)-Faculdade de Engenharia de Alimentos, Universidade Estadual de Campinas, Campinas, 2005.

MATTIETTO, R. A.; LOPES, A. S.; MENEZES, H. C. Estabilidade do néctar misto de cajá e umbu. Ciência Tecnologia Alimentar, v. 27 , n. 3, p. 456-463, 2007. http://dx.doi.org/10.1590/S010120612007000300006.

MELO, E. A.; ANDRADE, R. A. M. S. Compostos bioativos e potencial antioxidante de frutos do umbuzeiro. Alimentos e Nutrição, v. 21, n. 3, p. 453-457, 2010.

MINIM, V. P. R. Análise sensorial: estudos com consumidores. 3. ed. Viçosa: UFV, 2013. 308 p.

MORAIS, F. A.; ARAÚJO, F. M. M. C.; MACHADO, A. V. Influência da atmosfera modificada sob a vida útil pós-colheita do mamão "formosa". Revista Verde de Agroecologia e Desenvolvimento Sustentável, v. 5, n. 4, p. 1-9, 2010.

PINTO, W. S.; DANTAS, A. C. V. L.; FONSECA, A. A. O.; LEDO, C. A. S.; JeSUS, S. C.; CALAFANGE, P. L. P.; ANDRADE, E. M. Caracterização física, físico-química e química de frutos de genótipos de cajazeiras. Pesquisa Agropecuária Brasileira, v. 38, n. 9, p. 1059-1066, 2003. http://dx.doi.org/10.1590/S0100204X2003000900006.
REED, J. B.; HENDRIX, D. L.; HENDRIX JUNIOR, C. M. Quality control manual for citrus processing plants. Safety Harbor: Intercit, 1986. 250 p.

RUFINO, M. S. M.; ALVES, R. E.; BRITO, E. S.; PÉREZ-JIMÉNEZ, J.; SAURA-CALIXTO, F. D.; MANCINI-FILHO, J. Bioactive compounds and antioxidant capacities of 18-non-tradicional tropical fruits from Brazil. Food Chemistry, v. 121, n. 4, p. 996-1002, 2010. http://dx.doi.org/10.1016/j.foodchem.2010.01.037.

SACRAMENTO, C. K.; SOUZA, F. X. Cajá (Spondias mombin L.). Jaboticabal: Funep, 2000. 42 p. (Série Frutas Nativas, 4).

SAMPAIO, T. S.; NOGUEIRA, P. C. L. Volatile components of mangaba fruit (Hancornia speciosa Gomes) at three stages of maturity. Food Chemistry, v. 95, n. 4, p. 606-610, 2006. http:// dx.doi.org/10.1016/j.foodchem.2005.01.038.

SANTOS, T. C.; NASCIMENTO-JÚNIOR, J. E.; PRATA, A. P. N. Frutos da caatinga de Sergipe utilizados na alimentação humana. Scientia Plena, v. 8, n. 4, p. 1-4, 2012.

SILVA, E. E. Frutíferas nativas do Nordeste: qualidade fisiológica, morfologia e citogenética. 2006. 110 f. Dissertação (Mestrado em Agronomia)-Centro de Ciências Agrárias, Universidade Federal da Paraíba, Areia, 2006.

SILVA, N.; JUNQUEIRA, V.; SILVEIRA, N. F. A.; TANIWAKI, M. H.; SANTOS, R. F. S.; GOMES, R. A. R. Manual de métodos de análise microbiológica de alimentos e água. 4. ed. São Paulo: Livraria Varela, 2010. 614 p.

STONE, H. S.; SIDEL, J. L. Sensory evaluation practices. Florida: Academic Press, 1985. cap. 7, p. 227-252.

SWAIN, T.; HILLIS, W. E. The phenolic constituents of Prunus domestica L.: the quantitative analysis of phenolic constituents. Journal of Agriculture and Food and Agriculture, v. 10, n. 1, p. 63-68, 1959. http://dx.doi.org/10.1002/jsfa.2740100110.

TEMÓTEO, J. L. M.; GOMES, E. M. S.; SILVA, E. V. L.; CORREIA, A. G. S.; SOUSA, J. D. S. Avaliação de vitamina C, acidez e pH em polpas de acerola, cajá e goiaba de uma marca comercializada em Maceió-Alagoas. In: CONGRESSO NORTE NORDESTE DE PESQUISA E INOVAÇÃO (CONNEPI), 7., 2012, Palmas. Anais... Natal: Instituto Federal Rio Grande do Norte, 2012. p. 2. 